\title{
Study of Milling GH3039 on Milling Force with Ceramic Tool WG300
}

\author{
Jinghe $\mathrm{Li}^{1, \mathrm{a}}$, Wang $\mathrm{Xi}^{1, \mathrm{~b}}$, Min $\mathrm{Qi}^{2, \mathrm{c}}$ and Yubo Liu ${ }^{1, \mathrm{~d}}$ \\ ${ }^{1}$ School of Mechanical Engineering, Heilongjiang University of Science and \\ Technology, NO.2468 Puyuan Road, Harbin, 150022, China \\ ${ }^{2}$ Liaoning university of engineering and technology, Mechanical Engineering \\ institute, Fuxin city Liaoning province 123000,China \\ a58267123@qq.com, ${ }^{b}$ datkream@qq.com, ${ }^{\text {d } 543455430126 . c o m}$
}

\begin{abstract}
To nickel base superalloy in dry cutting, the milling experiment be done in the fouraxis machining center with ceramic tool WG300 is in order to know the influence of cutting speed to chip morphology through the macroscopic observation on chip by optical microscope and the analysis of chip morphology. Then, focus on the machining features of GH3039, reasonable orthogonal test be designed, after which getting the influence of different level's value to milling force and its change law based on the range analysis of experiment datum.
\end{abstract}

Keywords: Orthogonal Test, GH3039, Ceramic Tool WG300

\section{Instructions}

Nickel base superalloy is the superalloy which also called heat-resisting alloy or strong heat alloy, which contains over $50 \% \mathrm{Ni}$ in usual, while it is the most representative super heat-resisting alloy, also is the multicomponent complex alloy, which could work in the condition of high-temperature oxidation and gas corrosion between 600 to 1000 temperature based on its good strong thermal performance, thermal stability and thermal fatigue property, as well as the higher hardness, heat resistance and stain resistance. Thus, it is an important structural material in aviation, aerospace and ship-building industry which applies to the steam turbine and aeromotor [1].

For the features of low thermal conductivity and specific heat, high hightemperature strength, heavier work hardening, producing cut tumors easily, severer resistance to plastic flow and getting the good surface finish and precision difficultly, not only the cutting inefficiency, but the low cutting life are always the problem in machining. While through the analysis of cutting mechanism, difficultto-machine material machinability could be improved in a certain by high speed cutting technology [2].

To the experiment of milling nickel base superalloy GH3039 with ceramic tool, in the way of range analysis, studying the influence of values in different element and level to milling force and its change law, establishing the milling force empirical formula, which could be prepared for the cutting parameters optimization in daily practice. 


\section{Experiment Condition and Project}

\subsection{Experimental Facilities and Tool}

Test machine: Austria MC120-60 NC horizontal machining center, spindle power is $22.5 \mathrm{~kW}$, rotate speed is $50-12000 \mathrm{r} / \mathrm{min}$.

Tool: Green leaf WG300, diameter is $8 \mathrm{~mm}$.

Test system: The KISTLER 9257B three-component dynamometer. Installation of experimental facilities and detecting instrument shows in figure 1.

Ceramic tool has good heat resistance, abrasive resistance and higher hardness (9395HRC), which makes the machining of difficult-to-machine material like GH4169 and Gh3039 be possible. For its better chemical stability compares to hard alloy, ceramic tool extending the time of machining in high speed, which leading to the 3 to 10 times than the hard alloy in average processing efficiency ${ }^{[3]}$.

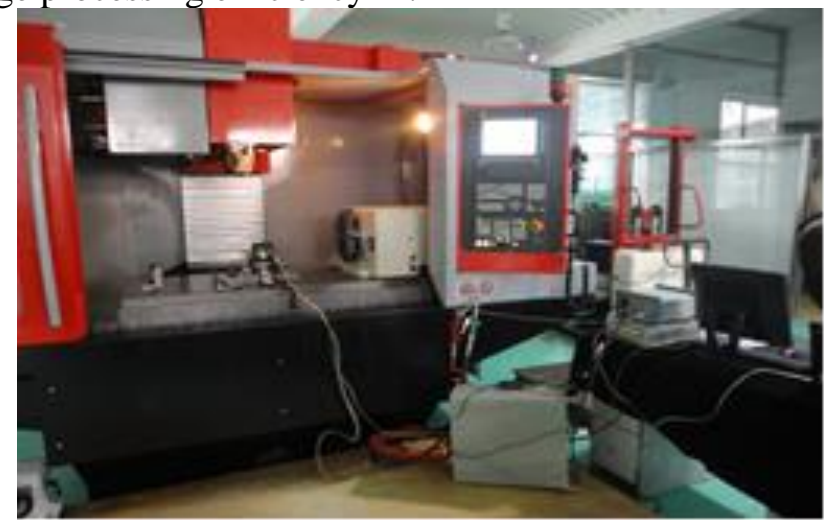

Figure 1. Installation of Experimental Facilities and Detecting Instrument

\subsection{Experimental Project}

The experiment of dry milling GH3039 with ceramic tool WG300 is done in machining center. The force datum will be got by the KISTLER 9257B threecomponent dynamometer during processing.

The way of milling is climb cutting. Milling project: To the processing features of nickel base superalloy, orthogonal test be designed to know the influence of each parameter to three-way milling force by range analysis, which will be prepared for choosing well parameters in practice. Milling parameter appears in table 1.

Table 1. Milling Parameter

\begin{tabular}{cccccccc}
\hline No. & $\begin{array}{c}\text { Axial } \\
\text { Doc } \\
a_{p}(\mathrm{~mm})\end{array}$ & $\begin{array}{c}\text { Radial Doc } \\
a_{e}(\mathrm{~mm})\end{array}$ & $\begin{array}{c}\text { Spindle } \\
\text { speed } \\
\mathrm{n}(\mathrm{r} / \mathrm{min})\end{array}$ & $\begin{array}{c}\text { Feed } \\
\text { Engagement } \\
f_{z}(\mathrm{~mm} / \mathrm{z})\end{array}$ & $F x$ & $F y$ & $F z$ \\
\hline 1 & 1 & 17 & 4500 & 0.1 & 1466 & 1269 & 638 \\
2 & 1 & 17 & 5000 & 0.12 & 1288 & 1254 & 483 \\
3 & 1 & 17 & 5500 & 0.15 & 1503 & 1684 & 637 \\
4 & 1 & 17 & 6000 & 0.17 & 1964 & 1979 & 881 \\
5 & 1.2 & 17 & 6000 & 0.15 & 1363 & 1166 & 302 \\
6 & 1.2 & 17 & 5500 & 0.17 & 1076 & 1481 & 351 \\
7 & 1.2 & 17 & 5000 & 0.1 & 1190 & 1204 & 387 \\
8 & 1.2 & 17 & 4500 & 0.12 & 2084 & 1886 & 963 \\
9 & 1.5 & 17 & 5000 & 0.17 & 1635 & 1377 & 236 \\
\hline
\end{tabular}




\begin{tabular}{llllclll}
\hline 10 & 1.5 & 17 & 4500 & 0.15 & 1225 & 1222 & 274 \\
11 & 1.5 & 17 & 6000 & 0.12 & 1220 & 1726 & 270 \\
12 & 1.5 & 17 & 5500 & 0.1 & 1478 & 1377 & 489 \\
13 & 1.7 & 17 & 5500 & 0.12 & 1694 & 1357 & 330 \\
14 & 1.7 & 17 & 6000 & 0.1 & 1502 & 1418 & 434 \\
15 & 1.7 & 17 & 4500 & 0.17 & 2164 & 2307 & 674 \\
16 & 1.7 & 17 & 5000 & 0.15 & 2254 & 2465 & 896 \\
\hline
\end{tabular}

When $V c=200 \mathrm{~m} / \mathrm{min}$, banding chip will be formed with whisker toughening ceramic tool WG300, which internal surface and outside surface are relative smooth as the figure 3 (a) shows. While in the similar milling speed, chip surface topography is also resemblance depicts in figure $3(\mathrm{a}, \mathrm{b}, \mathrm{c})$. To the function of milling speed to forming serrated chip, in one hand, the serrated chip will be easily formed for the adding milling speed, which lead to the strain speed enhanced, increasing its fragility finally; on the other hand, adding the milling speed has integrated impact to the trend of forming serrated chip, because of the increasing speed adds the chip temperature, resulting its fragility reduced [1]. After the observation of chip, the chip's saw level and warp are gradually strengthened and severer with the adding speed. In the figure 3, extrusion of chip surface material is strengthened with increasing speed. While $V c=290 \mathrm{~m} / \mathrm{min}$, serrated chip will be formed obviously. And $V c=320 \mathrm{~m} / \mathrm{min}$, adding speed enhanced the rubbing speed between chip and rake face, result in the milling temperature increased and pitch decreased, the yellow surface and narrow saw tooth chip be formed finally. When the milling speed increasing, the milling force will be reduced for the reason that it makes material soft, decreasing the rake face friction coefficient, leading to the cutting easily, which tells the linear law of reducing force with adding speed shows in fig.2.

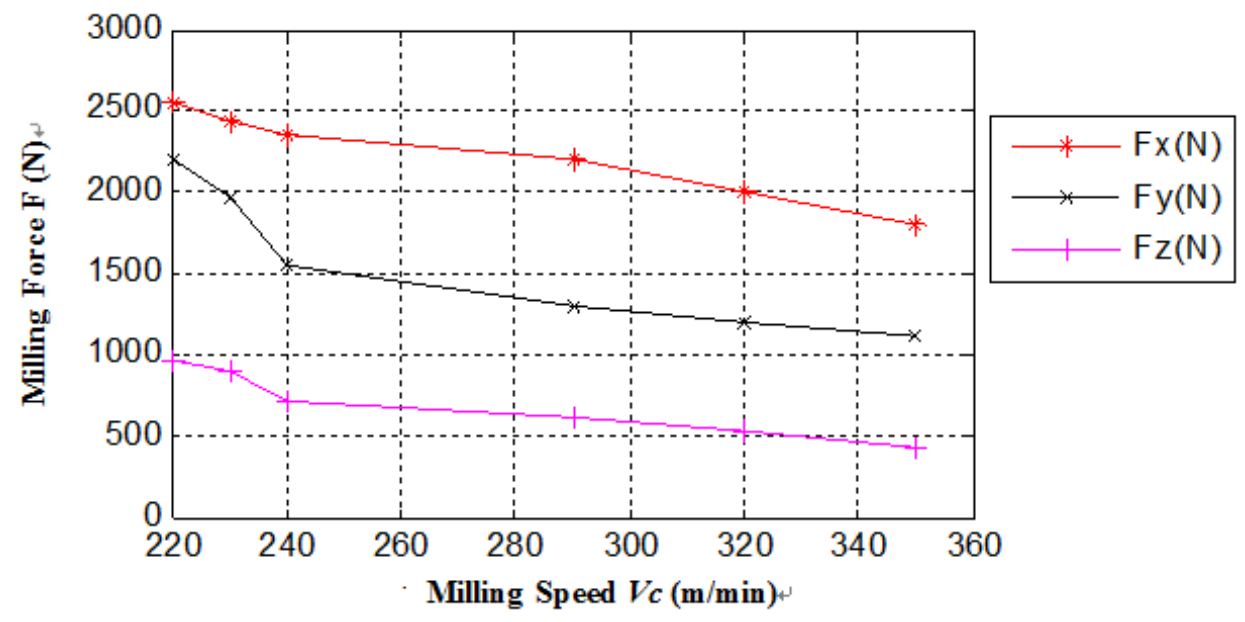

Figure 2. Influence of Milling Speed to Milling Force

\section{3. Range Analysis of Experiment}

According to table 1, the influence of parameter to three-way milling force could be figured out by range analysis. Focus on $F x$, depth of cut is the greatest influence, then is the feed engagement, and the least is spindle speed; To $F y$, the feed engagement is the greatest influence, then is depth of cut, and the least is spindle speed; For $F z$, depth of cut is the greatest influence, then is spindle speed, and the 
least is the feed engagement. Though the range analysis shows in table 2 , the best parameter of this experiment is $a_{p}=1.7 \mathrm{~mm}, n=4500 \mathrm{r} / \mathrm{min}$ and $f_{z}=0.17 \mathrm{~mm} / \mathrm{z}$.

In the way of range analysis, influence of milling parameter to milling force shows in fig. 4 ( $a, b, c)$, then it is easily to find that the affective of the value of each element in different level to milling force and its changing law.

In fig.4 (a, b, c), it is not different to find that the milling force is almost increasing with each parameter's adding, above all, the axial force Fz has little change, radial force $F x$ and circumferential force $F y$ are change a lot.

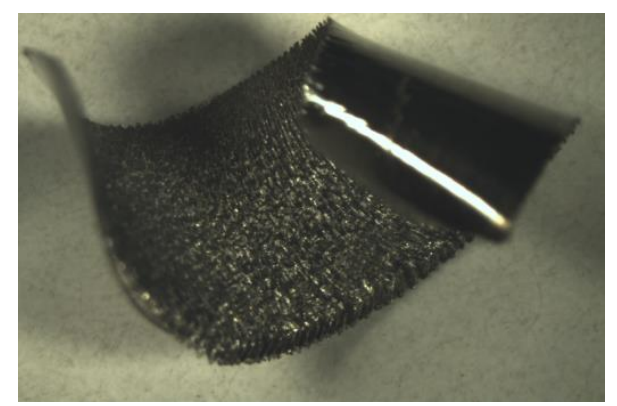

a. $V_{c}=200 \mathrm{~m} / \mathrm{min}$

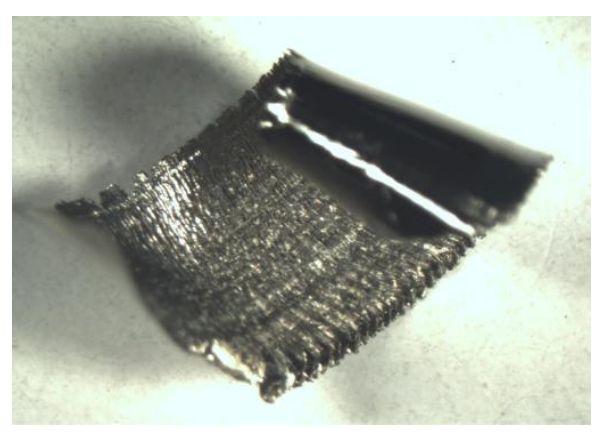

c. $\mathrm{Vc}=240 \mathrm{~m} / \mathrm{min}$

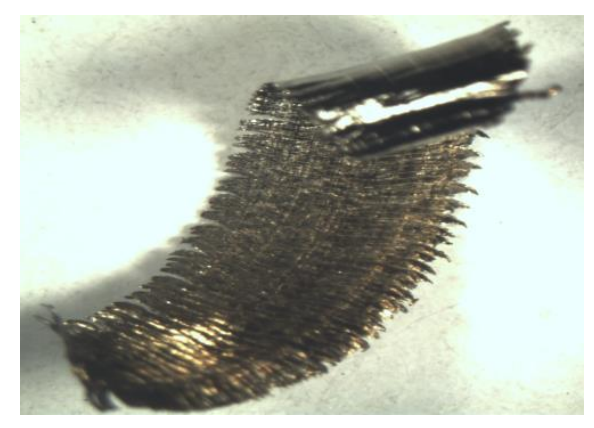

e. $V_{c}=320 \mathrm{~m} / \mathrm{min}$

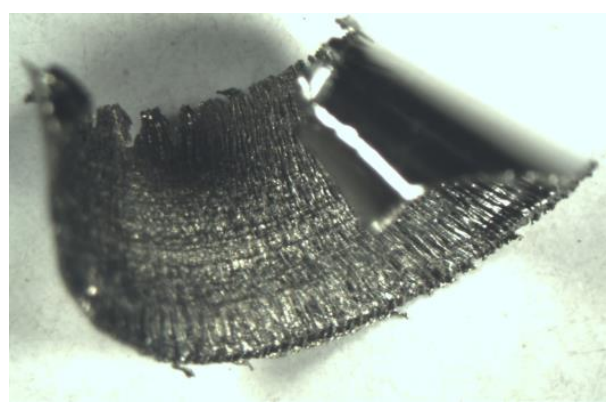

b. $V c=230 \mathrm{~m} / \mathrm{min}$

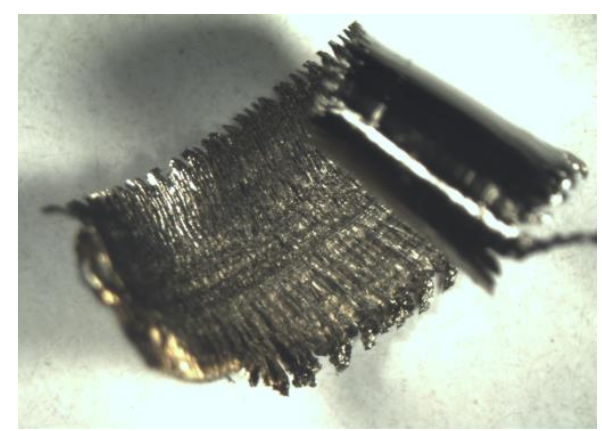

d. $V c=290 \mathrm{~m} / \mathrm{min}$

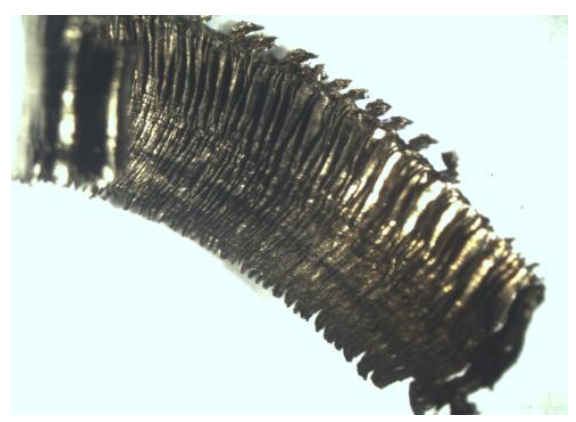

f. $V c=350 \mathrm{~m} / \mathrm{min}$

Figure 3. Chip Morphology in Different Milling Speed with WG300 


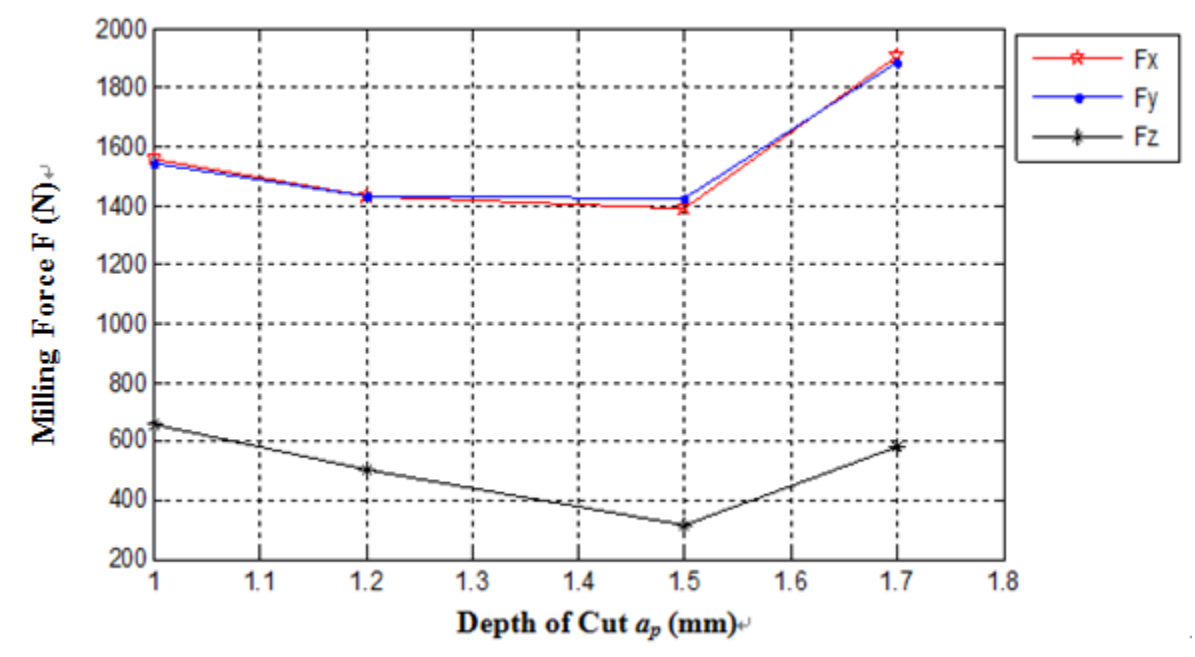

Figure 4. (a) Influence of Depth of Cut to Milling Force

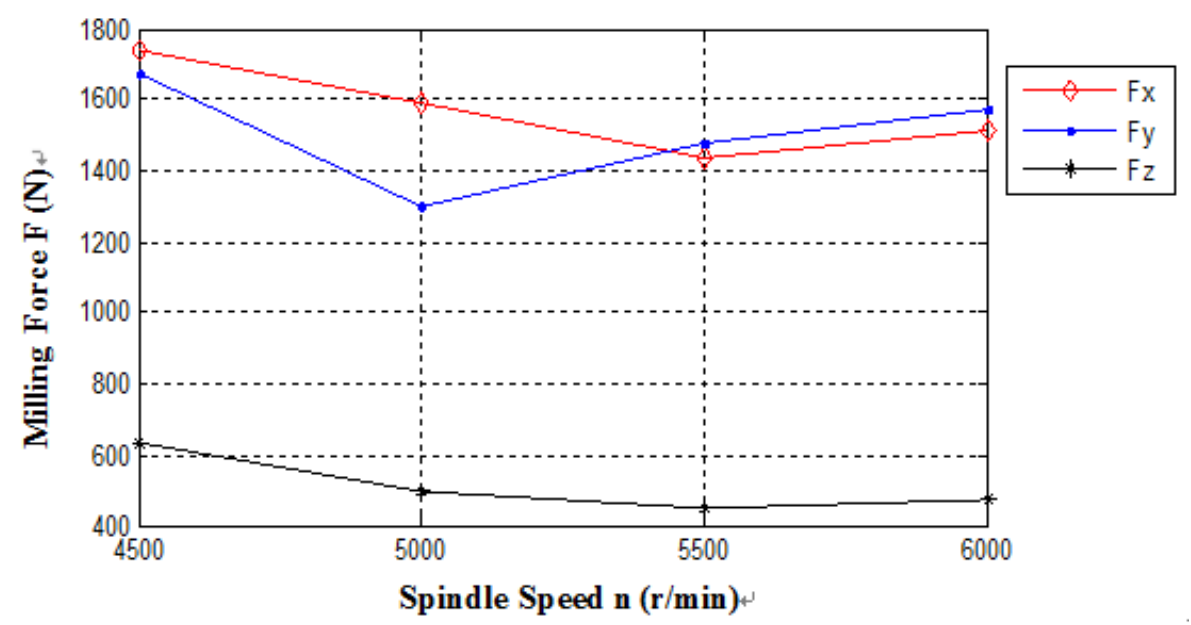

Figure 4. (b) Influence of Spindle Speed to Milling Force

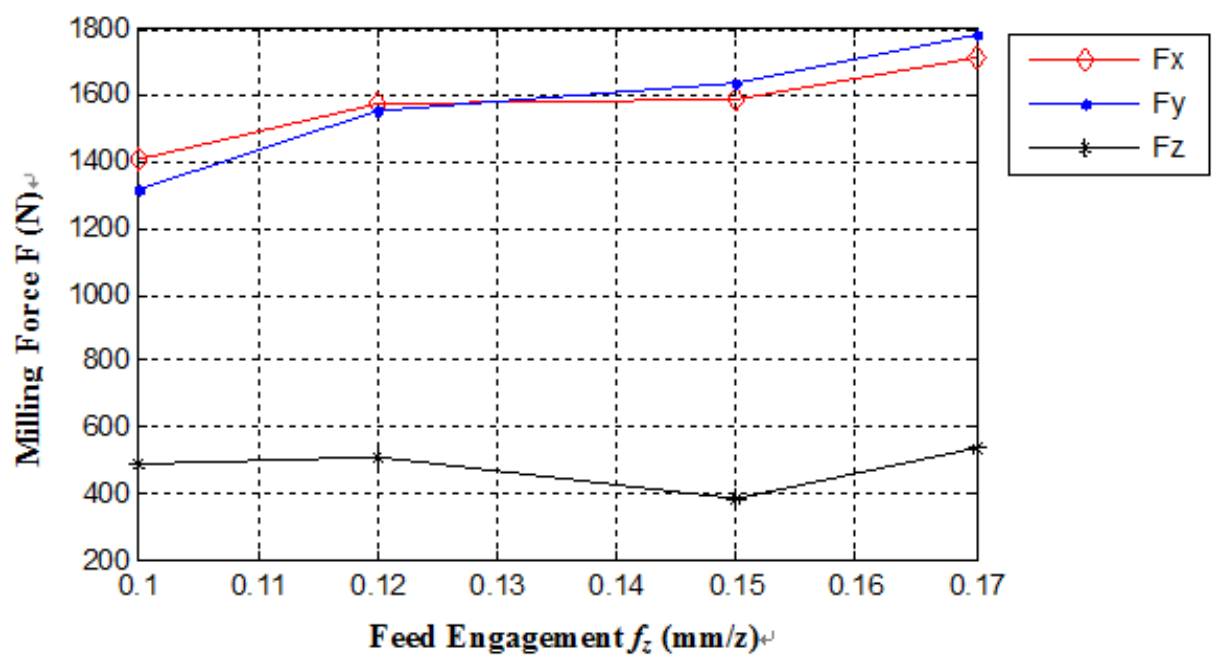

Figure 4. (c) Influence of Feed Engagement to Milling Force 
Table 2. Range Analysis of Orthogonal Test

\begin{tabular}{|c|c|c|c|c|c|}
\hline \multirow{2}{*}{$F$} & \multicolumn{5}{|c|}{ Depth of Cut } \\
\hline & 1 & 2 & 3 & 4 & Range \\
\hline$F x$ & 1555 & 1428 & 1390 & 1904 & 514 \\
\hline$F y$ & 1547 & 1434 & 1426 & 1887 & 461 \\
\hline $\mathrm{Fz}$ & 660 & 501 & 317 & 584 & 343 \\
\hline \multirow{2}{*}{$F$} & \multicolumn{5}{|c|}{ Spindle Speed } \\
\hline & 1 & 2 & 3 & 4 & Range \\
\hline$F x$ & 1735 & 1592 & 1438 & 1512 & 297 \\
\hline$F y$ & 1671 & 1298 & 1475 & 1572 & 373 \\
\hline$F z$ & 637 & 501 & 452 & 472 & 186 \\
\hline \multirow{2}{*}{$F$} & \multicolumn{5}{|c|}{ Feed Engagement } \\
\hline & 1 & 2 & 3 & 4 & Range \\
\hline$F x$ & 1409 & 1572 & 1586 & 1710 & 301 \\
\hline Fy & 1317 & 1556 & 1634 & 1786 & 469 \\
\hline$F z$ & 487 & 512 & 386 & 536 & 150 \\
\hline
\end{tabular}

\section{Conclusions}

Though the range analysis, the influence of the value of each element in different level to milling force and its law could be figure out, and the best parameter of this experiment is $a_{p}=1.7 \mathrm{~mm}, n=4500 \mathrm{r} / \mathrm{min}$ and $f_{z}=0.17 \mathrm{~mm} / \mathrm{z}$, which tells that the ceramic tool is suited to rough machining nickel base superalloy for improving production efficiency.

When the milling speed adding, extrusion of chip surface material is enhanced, and milling force reduced follow by linear.

\section{Acknowledgements}

This work was supported by the national natural Science Found (Project No 51075128 and 51405138) and the national Science Foundation of Heilongjiang Province (Project No QC2012C029).

\section{References}

[1] A. Xing, "High Speed Machining Technology", National Defense Industry Press, (2003).

[2] L. Zhibing, W. Xibin, and X. Lijing, "High Speed Cutting and Its Application for Difficult-to-cut Material”, New Technology \& New Process, vol. 1, (2006), pp. 46-18.

[3] H. Weijiu, "Quick Manual Mutter Materials", China Machine Press, (2011).

[4] China aviation materials manual, "Deformation of High Temperature Alloy", The China Standard Publishing House, (2001), pp. 194-195.

[5] X. Gang, "Experimental Study of Cutting Properties of Cermet Cutter", Huazhong University of Science and Technology, (2007).

[6] L. Peng, X. Jiuhua, F. Suling, F. Yucan and G. Guosheng, "Cutting Forces in High Speed Milling of Titanium Alloy with PCD Tool", Journal of Nanjing University of Aeronautics \& Astronautics, vol. 42, no. 2, (2010), pp. 224-229

[7] T. Duoliang, C. Zhaojie, and Z. Hongling, "Study on Experiment of Tool Life Test for Milling of Hightemperature Alloy Cutter of Nickel Base", Coal Mine Machinery, (2010), pp. 54-56

[8] Z. Xiufen and W. Yuhua, "Cutting of Nickel-Based High Temperature Alloy", Aeronautical Manufacturing Technology, vol. 11, (2010), pp. 46-50.

[9] X. Kai, L. Huiping and Y. Tianxue, "The Ceramic Tool Material and its Future Development", Rare Metals and Cemented Carbides, (2009), pp. 56-60.

[10] D. G. Thakur, B. Ramamoorthy and L. Vijayaraghavan, "Machinability investigation of Inconel 718 in high-speed turning”, Int J Adv Manuf Technol, vol. 45, (2009), pp. 421-429.

[11] J. H. Xu, K. Q. Ren and G. S. Geng, "Cutting Forces in High-speed Milling of a Close Alpha Titanium Alloy”, Key Engineering Materials, (2004), pp. 451-455. 